\title{
The promises and pitfalls of ecosystem-based adaptation to climate change as a vehicle for social empowerment
}

\author{
$\underline{S t e p h e n ~ W o r o n i e c k i ~}^{1}$, Christine Wamsler ${ }^{1,2}$ and Emily Boyd ${ }^{1}$
}

\begin{abstract}
Ecosystem-based adaptation (EbA) to climate change is an approach claimed to deliver social benefits relevant to marginalized groups. Based on a structured literature review, we interrogate such claims, asking whether such approaches may (or may not) contribute to social change and, more specifically, empowerment. We present a review of the predominant meaning and interlinkages of the EbA and empowerment concepts, which shows that EbA pays insufficient attention to issues of empowerment and agency. On this basis, we discuss how an empowerment lens could be (better) integrated into the conceptualization of EbA, suggesting key dimensions through which this could be supported. We show that the emphasis on empowerment theory and the merits that it brings to the EbA literature are helpful, leading to a number of important questions to adaptation projects on the ground. Incorporating an empowerment lens leads to an increased consideration of issues of power more broadly, especially the way marginalized groups' agency, access, and aspirations are conditioned by social structures that may prevent strategic adaptation choices. We conclude that EbA will facilitate empowerment better by explicitly considering how social benefits can emerge from the interplay between particular types of actions, marginalized people's adaptive strategies, and their relational context.
\end{abstract}

Key Words: agency; climate change; ecosystem-based adaptation; empowerment; nature-based solutions

\section{INTRODUCTION}

Climate change and inequality are interrelated challenges (Lovell and Le Masson 2014). Climate-related vulnerabilities are distributed unevenly across society, and the poor and marginalized are often disproportionately affected (Eriksen and O'Brien 2007, Olsson et al. 2014). The underlying causes of such vulnerabilities are said to be influenced by issues of power (LópezMarrero and Wisner 2012, Béné et al. 2016). Furthermore, vulnerability can be increased through adaptation and risk reduction processes (Coirolo and Rahman 2014, Conway and Mustelin 2014, Sovacool and Linnér 2016), leading to maladaptation (Atteridge and Remling 2018). This relates to the fact that adaptive capacity (the ability of systems, institutions, and humans to adjust or respond to potential climate change impacts, or to take advantage of opportunities) correlates strongly with existing power structures and indices of social, political, and economic marginalization (Moser 1998, White 2010).

Climate change and associated governance processes may not only reinforce inequality but, in certain circumstances, also offer opportunities to challenge it (Eriksen et al. 2015). However, whilst an increasing range of adaptation case studies highlight the importance of participation and knowledge sharing (Broto et al. 2015), there is a lack of theoretical and empirical scholarship that demonstrates how adaptation actions might contribute to disrupting in situ power relations, i.e., the particular context in which such actions take place, in order to address the vulnerabilities of marginalized groups.

Though power is increasingly recognized as a key mediator of efforts toward sustainable adaptation (Manuel-Navarrete 2010, Nagoda 2015, Boyd 2017), empowerment has, so far, received relatively scant attention in the academic literature on adaptation (important exceptions are Eriksen and O'Brien 2007, ManuelNavarrete 2010, Pelling 2011, Eriksen et al. 2015). This is surprising because, particularly under uncertainty, peoples' subjectively defined adaptive strategies (their agency) become progressively more important in adaptation action.

Definitions of empowerment recognize the messy political process of regaining agency in a wider social context, and emphasize that people's own worldviews (subjectivities) lie at the center of change. If empowerment is "the process by which people who have been denied the ability to make strategic choices acquire such an ability" (Kabeer 1999:435), then it would appear to offer both a useful analytical lens for analyzing how adaptation actions affect vulnerabilities for different groups amidst contextual power relations, as well as an explicit pathway for sustainable-adaptation practitioners to aim for (Eriksen and Lind 2009).

These relationships show the importance of integrated, holistic solutions that can move beyond the siloes of social or environmental sustainability (Carpenter et al. 2012, Patenaude and Lewis 2014, Preiser et al. 2017, Schleicher et al. 2018). In this context, nature-based solutions have risen to prominence, based on their apparent potential to deliver ever-elusive win-win solutions (Jones et al. 2012, Reid 2016, Díaz et al. 2018). Naturebased solutions are increasingly invoked as both sustainable and more inclusive than their infrastructural or technological alternatives, and include ecosystem-based approaches. In the context of climate change, ecosystem-based adaptation (EbA) is a form of adaptation designed to address vulnerabilities of at-risk people, including marginalized groups. EbA is said to be especially suitable for addressing the vulnerability of marginalized populations because of the high dependence of these groups on adjacent ecologies (Munang et al. 2014). It is also increasingly being highlighted by donors, policy makers, programmers, and scientists because of its ability to deliver multiple benefits (Andrade et al. 2011, Maes and Jacobs 2017, Wood et al. 2018). EbA includes, by definition, the "sustainable management, 
conservation and restoration of ecosystems, as part of an overall adaptation strategy that takes into account the multiple social, economic and cultural co-benefits for local communities" (CBD 2010:3).

From an empowerment perspective, the claims that EbA can deliver social benefits for marginalized groups are especially interesting (Munang et al. 2014). However, although these claims occur with increasing regularity (Doswald et al. 2014, Seddon et al. 2016), their theoretical and empirical validity has received very little attention (Brink et al. 2016).

Against this background, in this paper we assess the potential role of $\mathrm{EbA}$ to contribute to the empowerment of marginalized groups. More specifically, based on a targeted literature review, we assess the meaning of EbA and interlinkages with empowerment concepts.

The resultant synthesis is relevant for EbA scholars and professionals interested in how such approaches might facilitate transformations toward safe and just futures (O'Brien 2012). We discuss conceptual approaches to agency and social change amidst dynamic biophysical processes and changing ecosystem services under climate change. We make an initial attempt to understand how EbA may articulate with a rich and dynamic social-ecological context, and how those articulations might play out for the vulnerabilities of particular groups.

\section{METHODS}

Below, we set out how the literature review was conducted and the common ground (theoretical and methodological assumptions) that links the fields of EbA and empowerment. We start by setting out the analytical framework used to assess and link the two concepts, and then show how it was applied to capture how the literature treats these links and, thus, the resulting gaps.

\section{Analytical framework}

Our work examines the apparent affordances of EbA in addressing the adaptation needs of the most vulnerable, and contributions to their empowerment. The analysis is based on a shared problem formulation. Namely, if adaptation is understood as the process by which people reduce their vulnerabilities, then the role and relevance of both EbA and empowerment become apparent. We understand agency as relational; it is not owned by particular individuals, but conditioned by contextual power relations that have an ecological and social dimension. Similarly, EbA and empowerment processes are influenced by relations of power that work across biophysical (ecological), institutional, and discursive (social) dimensions. Such relations shape, and are shaped by people's experience of vulnerability and marginalization. The analytical framework was constructed according to three key assumptions (i-iii) deduced from the literature.

(i) Power relations are central in producing vulnerability, and adaptation to climate change is, itself, a power-laden process.

Vulnerability is embedded in, and shaped by, contextual power processes and relations that both precede and strongly influence the impacts of climate change. Power is a complex and ambivalent notion, defined here as "asymmetrically structured agency" (Stirling 2014:84) and characterized as a relational process that has both an enabling (power to, or agency) and constraining (power over) function in adaptation (Hayward and Lukes 2008, Pansardi 2012). Power is reflected in social-ecological relations under climate change that define a person's vulnerability. Dynamic power relations shape the root causes, unsafe conditions, and processes driving the vulnerabilities of specific people (López-Morrero and Wisner 2012). Ribot (2014:667) summarizes this position as "[a]ttention to anthropogenic climate change should not occlude social causes of (and responsibility for) vulnerability - vulnerability is still produced in and by society."

The social-ecological relations that influence differential vulnerability can be both positively and negatively influenced by the relations of power between social groups and individuals (Forsyth 2014). Power is represented, for example, in access to resources that can determine adaptive capacity (Adger et al. 2005, Eyben et al. 2006, Eakin et al. 2014).

(ii) Adaptation actions may intentionally or unwittingly disrupt the power relations of a given context.

Given the above relationship between vulnerability and power, empowering vulnerable groups becomes even more important under climate change because people's subjectively defined agency is important in dealing with evolving contexts (ManuelNavarrete 2010, Stirling 2015). Social change, in the form of empowerment, is a process through which power relations shift, with meaningful consequences for actors and their vulnerabilities to climate change impacts.

(iii) Social benefits emerging from EbA result from recursive changes in power that are embedded in social-ecological relations.

These shifts play out across social-ecological relations. Though nature or ecosystem-based approaches invoke the power of ecology, the emphasis on ecology should not hide the fact that these EbA can represent discrete ecologically orientated adaptation actions or interventions, with both institutional and normative, i.e., politically symbolic, discursive, dimensions (Polishchuk and Rauschmayer 2012, Brink et al. 2016, Wieland et al. 2016). These actions, which are focused on strengthening or securing particular ecological processes, are institutional in the sense that they require particular sets of rules and norms, and discursive in that they involve particular sets of values in regard to social-ecological relations. This is consistent with scholarship that recognizes that humans are embedded within ecosystems, and continuously make subjective decisions in order to perpetuate flows of beneficial services and reduce harm.

\section{Literature review}

On the basis of the analytical framework, a targeted literature review was used to locate and analyze relevant articles. The Web of Science and Scopus academic databases were searched for relevant peer-reviewed articles, both conceptual and empirically focused. Searches were conducted during 2016 in order to identify articles that dealt explicitly with either "ecosystem-based adaptation" or "empowerment" in their abstract, keywords, or titles. This query was further refined according to inclusion and exclusion criteria applied initially to abstracts, and then full texts. The inclusion and exclusion criteria were based on the definitions of each concept as set out in the analytical framework, or constitutive elements of each concept. Similarly, articles were 
Table 1. Overview of review findings according to the three-dimensions of power framework. Ecosystem-based adaptation (EbA) offers preconditions for empowerment processes. Empowerment scholarship demonstrates what is required for social change to occur. This has implications for EbA to become aligned toward these sensitivities.

\begin{tabular}{|c|c|c|c|}
\hline Dimension of power & $\mathrm{EbA}$ & Empowerment & Implication \\
\hline Material & $\begin{array}{l}\text { EbA claims to deliver multiple types of } \\
\text { social benefits, addresses needs of the } \\
\text { poorest, and minimizes negative effects. }\end{array}$ & $\begin{array}{l}\text { Agency and access to tangible and } \\
\text { intangible resources. A changing social- } \\
\text { ecological context for capabilities. }\end{array}$ & $\begin{array}{l}\text { Reframing adaptive capacity in terms of } \\
\text { agency, access. }\end{array}$ \\
\hline Institutional & $\begin{array}{l}\text { EbA encompasses a wide variety of pro- } \\
\text { poor livelihood measures and actions, } \\
\text { and can more easily incorporate local } \\
\text { knowledge and priorities. }\end{array}$ & $\begin{array}{l}\text { Engagements of knowledge and } \\
\text { participation. Process ownership and } \\
\text { institutional disruption. }\end{array}$ & $\begin{array}{l}\text { Ensuring forms of engagement enable } \\
\text { people's struggles and rights claims. }\end{array}$ \\
\hline Discursive & $\begin{array}{l}\text { EbA is flexible and holistic, works well } \\
\text { with participatory and locally sensitive } \\
\text { forms of engagement, and integrates } \\
\text { with wider development and adaptation } \\
\text { strategies. }\end{array}$ & $\begin{array}{l}\text { Recognition of political nature of rights } \\
\text { claims. }\end{array}$ & $\begin{array}{l}\text { Reframing recognition to acknowledge } \\
\text { the relational character of people's needs, } \\
\text { dependencies, priorities, and aspirations. }\end{array}$ \\
\hline
\end{tabular}

included if they dealt with social aspects of EbA, or their social or multiple benefits, or described implementation processes. Technically focused and natural science articles were excluded. The initial list was checked by reading manuscripts and full texts to ensure their relevance. Full texts were analyzed qualitatively. Articles were included until saturation was reached (no further insights were added by subsequent papers).

Nonpeer reviewed material published by leading authorities driving conceptual developments in the field were also considered, e.g., the United Nations Convention on Biodiversity. This supplementary material was identified through the information provided in the academic literature. Overall, the review resulted in more than 90 articles from both databases included in the final review, after applying inclusion and exclusion criteria. Each article was read and evaluated by the first author of this paper, guided by the framework. Related outcomes were then reviewed and, where appropriate, revised by all authors.

\section{FINDINGS}

\section{EbA vis à vis empowerment}

This section presents the findings of the review, beginning with how EbA is constructed in relation to empowerment. Our structured literature review identified three key pillars: (i) EbA's multiple, socially oriented benefits, (ii) its pro-poor livelihood approach, and (iii) its participatory and locally sensitive character. Table 1 provides an overview of these three aspects and associated claims in relation to our analytical framework.

\section{Multiple social benefits of EbA}

Our review of the literature confirmed that EbA scholars have constructed the concept around, inter alia, explicit social and cobenefits that are relevant when addressing the vulnerabilities of people experiencing marginalization, social-exclusion, or poverty. In some cases, such as the definition from the Convention of Biological Diversity Secretariat, social benefits are seen as a constitutive element of EbA (CBD 2010). This is in addition to related claims that could be classed as socioeconomic, such as the provision of food and water security, livelihoods, economic development, or poverty alleviation (Uy et al. 2012, Renaud et al. 2013). In one case, Munang et al. (2014) state that the implementation of EbA in Togo actually led to "countless social benefits." In a systematic review of EbA, Doswald et al. (2014) find, for instance, "considerable evidence" of EbA's ability to deliver social, environmental, and economic cobenefits. Munang et al. (2014) present the broadest empirical evidence of social benefits. Based on data from Africa, the authors present 16 social benefits, grouped into four categories, relating to (i) local actor empowerment, (ii) livelihoods, (iii) food security, and (iv) sustainable development.

Overall, the reviewed literature cites both theoretical and empirical examples of how EbA interventions can lead to progressive social change (the process through which social relations are maintained or enhanced with progressive outcomes for marginalized groups). Examples of "multiple benefits" of the ecosystem-based approach are apparent in both empirical and theoretical scholarship (Doswald et al. 2014). In total, we identified four papers that made explicit reference to empowerment (Roberts et al. 2012, Munang et al. 2014, Brink et al. 2016, Reid 2016). Typically, references related to supporting livelihoods, diversification, and poverty alleviation (Tompkins and Adger 2004, Uy et al. 2012). Gender equality was mentioned less frequently (Munang et al. 2014). References were also made to sustainable development (Munang et al. 2014, Seddon et al. 2016) and conflict resolution (Reid 2016) mirroring the burgeoning literature on "green peacebuilding" (Tidball and Krasny 2014) and social cohesion (Reid 2016).

However, it became apparent that the evaluation criteria used to judge social benefits were either mixed with socioeconomic indicators, or simply nonexistent. Much of the evidence for social benefits is anecdotal (e.g., Munang et al. 2014). In cases where social benefits are explicitly mentioned (e.g., Mercer et al. 2012, Doswald et al. 2014, Munang et al. 2014, Seddon et al. 2016), little empirical evidence is presented, and there is a lack of transparency regarding the qualitative or quantitative methodology, and the social processes that underpin outcomes (for instance, the social inclusion benefits presented in the case of Togo by Munang et al. 2014).

In fact, we observe a dearth of theoretical and empirical data, notably as evidence of the social processes that may underlie social-benefits, i.e., social change, outcomes. Although we found direct and indirect references to empowerment, we found little (or 
no) empirical documentation of how these social changes emerged in the contexts in which EbA was deployed.

\section{EbA as a pro-poor adaptation strategy linked to climate-affected livelihoods}

Our review found that both research and practice share a common emphasis on the pro-poor, inclusive character of EbA. It is deemed appropriate in addressing the needs of the very poorest and most socially marginalized groups, including in responding to climate change and building adaptive capacity (Munang et al. 2014, Brink et al. 2016, Reid 2016). We also observed instances of EbA having "less negative effects" or reduced costs compared to other approaches (Jones et al. 2012, Doswald et al. 2014). This may count as a pro-poor social benefit because marginalized groups tend to be more vulnerable to the negative effects of adaptation actions (maladaptation), because they are less involved in decision making and least able to resist detrimental actions (Brink et al. 2016).

The review confirmed that EbA contributes to people's physical and livelihood security amidst a changing biophysical context, especially for marginalized groups. Our review also showed that EbA has been framed mostly through the lens of ecosystem services, focusing on their protective and facilitative function in relation to climate-affected livelihoods, such as agriculture, fisheries, and forestry (Uy et al. 2012, Girot 2013, Renaud et al. 2013). In this context, $\mathrm{EbA}$ is formulated around the principle of considering ecological functions and processes as part of strategies that are designed to proactively address climate change impacts. In this context, a major perceived advantage in relation to empowerment is that $\mathrm{EbA}$ recognizes, and builds upon, the scientific understanding that humans are part of the environment and, as such, that security and justice concerns are implicitly interlinked to the status of the biosphere across multiple spatial and temporal scales, in myriad ways (Jones et al. 2012, Renaud et al. 2013, Doswald et al. 2014, Brink et al. 2016).

The review highlighted that EbA scholars often construct a mandate for ecosystem-based solutions based on the dependence of the rural poor on ecosystem services for their livelihoods, and the threat to these services posed by climate change (Jones et al. 2012, Doswald et al. 2014). In fact, EbA initially emerged from an understanding within the global south, with proponents arguing that $\mathrm{EbA}$ could be a way to support poor communities who are often directly dependent on the environment (Vignola et al. 2009, Jones et al. 2012, Forsyth 2014). In addition, because natural-resource dependent livelihoods are most vulnerable to changes in climate (Renaud et al. 2013), and these tend to be associated with the most marginalized, poorest, and rural groups, in principle this provides a mandate for $\mathrm{EbA}$, especially if $\mathrm{EbA}$ actions are integrated with wider adaptation and development concerns (CBD 2009).

\section{EbA as a participatory and locally sensitive approach}

Because we found little evidence of how the aforementioned social changes emerge, we are left to infer the mechanisms, and we did so by applying our analytical framework to the papers. This approach to the literature review of EbA theory provides evidence that it may enable new kinds of discursive politics and institutional engagements. For instance, guidance on EbA implementation emphasizes knowledge integration and participation as potentially empowering mechanisms. These discursive and institutional orientations may support marginalized peoples, and provide the entry point for understanding the social processes that bring about social change. Our review also found that $\mathrm{EbA}$ is often claimed to foster locally sensitive approaches that consider people's local knowledge and priorities (Uy et al. 2012, Chong 2014). This community-based orientation highlights how people's agency is being considered implicitly (Ensor and Berger 2009). Underlying this is the recognition that ecosystem services represent a wide variety of measures that are closely integrated with people's livelihoods and practices (Girot 2013, Díaz et al. 2018) Accordingly, a wide body of related literature emphasizes the potential social gains of community-based natural resource management (Pretty and Ward 2001, Jones et al. 2012).

Consequently, scholars have often positioned EbA as potentially inclusive and participatory, given that ecosystems can be managed jointly and in traditional ways (Tompkins and Adger 2004, Uy et al. 2012). This is not possible with alternative "grey" approaches that rely on expensive and/or technical solutions such as maintenance of storm protection levees or the development of drought-resistant hybrid seed varieties (Jones 2012, Girot 2013) Indeed, the review found that in both its institutional forms and the literature on its institutionalization, EbA emphasizes the importance of participatory mechanisms, knowledge sharing, and compatibility with community-based adaptation (Mercer et al. 2012, Reid 2016). EbA appears to consider expertise around adaptation measures as equally dependent on local and extralocal knowledge, rather than biased toward the latter (Mercer et al. 2012).

In sum, our findings regarding EbA vis à vis empowerment are as follows:

- EbA claims to deliver multiple types of social benefits, is well-positioned to address the needs of the poorest, and minimizes negative effects.

- EbA encompasses a wide variety of pro-poor livelihood measures and actions, and can more easily incorporate local knowledge and priorities.

- EbA is flexible and holistic; it works well with participatory and locally sensitive forms of engagement, and integrates with wider development and adaptation strategies.

\section{Empowerment vis à vis $\mathbf{E b A}$}

In the previous section we introduced some dimensions of $\mathrm{EbA}$ that appear to be linked to its claims of social benefits for marginalized groups. These include, principally, its anchoring in social-ecological relations (especially livelihood dependencies) and the apparent comparative advantages of EbA actions in terms of the engagements it affords marginalized groups, i.e., locally sensitive decision making incorporating a plurality of knowledge systems.

The previous section also identified several gaps in the literature. These concern the role of power within social-ecological relations (and the shaping of vulnerability), the role of the EbA implementation process itself, and the recognition of people's diverse strategies and ways of relating to ecology. According to our conceptual framework, these are expressions of the biophysical, institutional, and discursive dimensions of power. 
Next, we turn to our review of the empowerment scholarship as a way to systematically and explicitly account for how power relations, operating across social-ecological relations, might be affected by an adaptation action (EbA or otherwise).

\section{Agency and access amidst a changing biophysical context relevant to $\mathbf{E b A}$}

Our review reveals that the biophysical-ecological basis of vulnerability and adaptation that is central to the conceptualization of $\mathrm{EbA}$ is only a partial view. It is partial because it does not take into account the ways in which social and ecological relations interplay within vulnerability and adaptation processes. Nor does it take into account the roles of power within such social-ecological relations. Empowerment theory informs such notions.

In the empowerment scholarship, power is viewed as a dynamic and evolving social force, conditioning the distribution of entitlements, access, and resources and, in turn, being shaped by its performance (Giddens 1984, Leach et al. 1999, Stirling 2015). In the context of EbA, access to ecosystem services and their conversion into adaptation strategies is mediated through such power relations. Many intervening social factors can interrupt the achievement of aspirations (Giddens 1984, Leach et al. 1999, Sen 2001). The empowerment scholarship demonstrates that by using an institution/ access lens, we can understand the particular ways that access is differentiated in society (Onta and Resurreccion 2011, Codjoe et al. 2012, Ensor et al. 2015). One example is the way in which gendered social structures condition the ways that men and women have access to different types of resource, as well as the pathways through which these can be converted into achievements, including adaptive strategies (Roy and Venema 2002, Polishchuk and Rauschmeyer 2012). Such structures condition how different groups manifest their agency, including ethnicity, gender, and age (Onta and Resurreccion 2011, Codjoe et al. 2012, Ensor et al. 2015).

The review also reveals how agency is enacted (performed) in daily practices, livelihood strategies, collective actions, including practices for managing ecosystems (Agarwal 2010, Tanner et al. 2015). In the context of EbA, it is expressed in social-ecological relations, including for others, and in the future. Furthermore, the enaction of agency (also termed power to), whilst important for "getting things done" (Gaventa 2006, Stirling 2015), is also related to power over others, deliberately or unwittingly, because it influences other peoples' conduct, as well as their respective social-ecological context (Giddens 1984, Leach et al. 1999, de Hann and Zoomers 2005, Haugaard 2010, Pansardi 2012, Bourdieu 2014). Although EbA scholarship has a focus on ecological resources, empowerment scholarship demonstrates that both ecological and nonecological, and tangible or intangible resources, operating as capital, can be important for social action (Chambers and Conway 1991, Gabriellson and Ramasar 2013).

\section{Engagements relevant to $\mathbf{E b A}$}

Our review revealed that EbA fails to pay sufficient attention to the process of adaptation action itself, including the role of the implementation of EbA interventions. The role of institutions is highly relevant to the practice of $\mathrm{EbA}$ and empowerment. Empowerment theory provides some insights into the institutional dimensions of power that are invoked in such processes; in particular, it highlights the way that EbA processes represent engagements.
Empowerment scholarship argues that social change in adaptation contexts is represented by disruption to in situ power relations that impact on marginalized people's vulnerability (Kabeer 1999, Eriksen and O'Brien 2007, Eriksen et al. 2015). Empirical case studies show that adaptation actions may disrupt such relations, with progressive consequences for the vulnerability of already marginalized groups (Gaillard et al. 2013, Chu et al. 2016). However, our review shows that such actions are more likely to repeat patterns of exclusion and marginalization than challenge them (Amundsen et al. 2010, Ahammad 2011, Eakin et al. 2011, Harries and Penning-Rowsell 2011, Mukheibir et al. 2013, Snorek et al. 2014, Wamsler and Brink 2014). Empowerment scholarship shows how such disruptions may occur as a result of, or despite, the formal engagements of an EbA intervention (participatory processes, knowledge exchange, and attention to people's risk priorities, values, and needs; Pelling 2011). It shows why adaptation actions are more likely to reaffirm these dominant social structures than support such claims and struggles. Unless these are brought into play as part of (or despite) adaptation actions, such structures are likely to remain in place, and condition the risks and opportunities that arise from adaptation action. The power relations of a given place are likely to be dynamic: a set of semipermanent social structures (institutions, discourses) and other processes, which people marginalized by structures struggle to negotiate, contest, or overturn (Kabeer 1999, Gabriellson and Ramasar 2013). Such struggles are likely to be an important part of marginalized people's adaptation strategies, which are, in turn, a response to subjectively experienced stresses, risks, and opportunities, and address particular needs and aspirations.

Scholars emphasize the importance of so-called procedural justice, or "getting the institutions right" (Paavola and Adger 2006). Ultimately, the scholarship suggests that just institutions that facilitate the representation and recognition of marginalized people's voices and priorities are most likely to contribute to people's own struggles for empowerment (Vogel et al. 2007, Bhave et al. 2013, Gaillard et al. 2013, Broto et al. 2015). Nancy Fraser, for instance, understands that facilitating empowerment is about achieving representation in decision making, alongside equal distribution of resources, and recognition of claims to rights and the priorities of various groups in a process (Fraser 1997, see also Schlosberg 2004, Paavola and Adger 2006). Acknowledging the link between engagements and contextual power relations, a wide body of scholarship focuses on the implications of such forms of engagement for justice (Arnstein 1969, Newsham and Thomas 2011, Sova et al. 2015), including in the contexts of adaptation and environmental management (Schlosberg 2004, Paavola and Adger 2006). These may relate to how diverse forms of knowledge are equated, or not (Eriksen et al. 2015, Nightingale 2017). Just processes of decision making, which accommodate the perspective and priorities of various groups, are key to balancing power within an adaptation action (Petheram et al. 2010, Brugger and Crimmins 2013, Broto et al. 2015). Various examples show how formal engagements, such as livelihood support, participatory processes, or knowledge integration can lead to broader social changes (Ahmed 2001, Agarwal 2010). Such articulations can happen simultaneously across different types of power structures, and at different scales.

A longstanding body of literature clearly demonstrates the links between reducing vulnerability and obtaining rights (Watts and 
Bohle 1993, Cannon 1994, Ribot 2010). The redistribution of rights and access occurs through a change in the recognition of marginalized groups' needs and priorities, and their resultant representation in decision-making spaces (Agarwal 2010). EbA itself can act as a catalyst for change, either by facilitating processes that lead to broader structural change, or acting as an object against which struggles for recognition and resistance play out. The struggle against such social structures is unlikely to be supported unless the politics of broader social structures, i.e., access conditions for particular ecosystem services, are somehow brought into play, in a manner that allows them to be challenged rather than reified, as part of EbA action. Importantly, however, the scale of an intervention may differ from the scale of institutions in which power is perpetuated and contested, limiting, inter alia, the potential for an adaptation intervention to lead to social change (Forsyth 2014, Wamsler and Brink 2014).

\section{Politics and recognition relevant to EbA}

Our review revealed that EbA pays insufficient attention to how people's agency, ecology, dependency, and vulnerability are framed. Framing is highly relevant to the practice of EbA and empowerment, overlapping with issues of values, meanings, and subjectivities. Empowerment theory provides an insight into how the framing of social-ecological relations is a political and symbolic process. Marginalized people are enabled or constrained by certain frames or discourses. Empowerment demonstrates the importance of recognition in the relation between $\mathrm{EbA}$ and people's broader strategies, designed to address vulnerability, security, and justice.

In the context of vulnerability and adaptation, we find that empowerment has often been framed as an apolitical process of capacity development, or even delivery. In Kabeer's influential definition, empowerment is the contingent, political process "by which those who have been denied the ability to make choices acquire such an ability" (Kabeer 1999:437). According to Drydyk (2008) empowerment is always deployed as a concept with a view to undoing the structural disempowerment of particular groups, and always with a view to facilitating actors' own strategic achievements. Such processes can be characterized by struggles about meaning (Tilly 2005, Manuel-Navarrete 2010, Schwarz et al. 2011). Empowerment can be a combination of changing discourses and representations, including building self-awareness and self-confidence ("power within"), and a greater ability to change the representations and legitimacy of marginalized groups' voices in wider society (Veneklasen 2006). Such issues can be expressed across a variety of platforms, including institutions that govern natural resource use.

In sum, our findings regarding empowerment vis à vis $\mathrm{EbA}$ emphasize the following:

- A greater focus on agency and access to resources within a changing social-ecological context for capabilities.

- EbA entails engagements with diverse groups within broader contexts that may or may not be empowering.

- Marginalized people's struggles concern symbolic as much as biophysical resources.

\section{DISCUSSION}

Our review demonstrates that altered biophysical conditions, as well as new kinds of discursive politics and institutional engagements may be made possible through EbA. Empowerment scholarship provides an insight into how such changes may be more clearly theorized. In this section, we discuss the changes that such nuancing requires on the part of EbA researchers and practitioners.

EbA emphasizes the ecological basis of people's vulnerability, while empowerment theory highlights the links between vulnerability and marginalization, addressed through disruption in power relations. One blind spot of EbA, when seen from the vantage point of empowerment, is that this ecological dimension is only one component of power, and little attention is paid to either discourse or institutions. However, both EbA and empowerment present a partial view, and neither provide conceptual clarification regarding how the social and ecological coalesce in dynamic relations, especially within EbA actions, and how this affects the vulnerability of marginalized groups.

Our review confirms that EbA may enable social benefits. The literature on empowerment shows how this may occur. We observe that the key issue is how the affordances and potentialities of EbA are embedded within broader power dynamics. These same power dynamics condition entitlement and access for different groups, with implications for the exacerbation or remediation of the marginalization and vulnerability encountered by these groups. We note that EbA pays little attention to the relational character of power, which is surprising given its apparent pro-poor focus. Despite the implicit recognition of the role of power (within social-ecological relations), it appears that EbA struggles to recognize how its own methods translate into possibilities and constraints for empowering processes. Our study confirms that claims regarding the social benefits of EbA could emerge from the propensity for participation, knowledge integration, and the recognition of local strategies and risk priorities. We consider these aspects as representative of "preconditions for empowerment." The empowerment lens extends our understanding of such preconditions beyond EbA actions, for instance, by focusing on the entitlements of marginalized people, including in relation to ecological dimensions of vulnerability.

Such issues become relevant given that $\mathrm{EbA}$ is often an intervention and, as such, shares various discursive and institutional issues with other development and adaptation approaches. Although EbA may enable certain affordances, it does not escape from the issues that affect adaptation found in other approaches. The potential for social benefits is enabled or constrained by such discursive and institutional conditions. To honor this potential, actors that are embedded within particular adaptation and development discourses, paradigms, and practices may have to change. An empowerment lens provides the framework to undertake such discursive and institutional work, starting with the questions presented in Table 2.

\section{Discourse}

We suggest a repositioning of EbA relative to narratives of agency and dependency. Both of the latter link to discursive dimensions of $\mathrm{EbA}$, which, in turn, link to broader power dynamics of recognition and representation. Empowerment cannot be delivered because it is understood as emerging from within. Framing empowerment as a deterministic outcome of a particular kind of adaptation may be counterproductive because it may empower EbA practitioners while contributing to a lack of recognition and representation of marginalized people's diverse 
Table 2. A checklist for ecosystem-based adaptation (EbA) researchers according to the empowerment lens, which we posit can enable $\mathrm{EbA}$ to better act as a vehicle to deliver on its claims of socially orientated benefits.

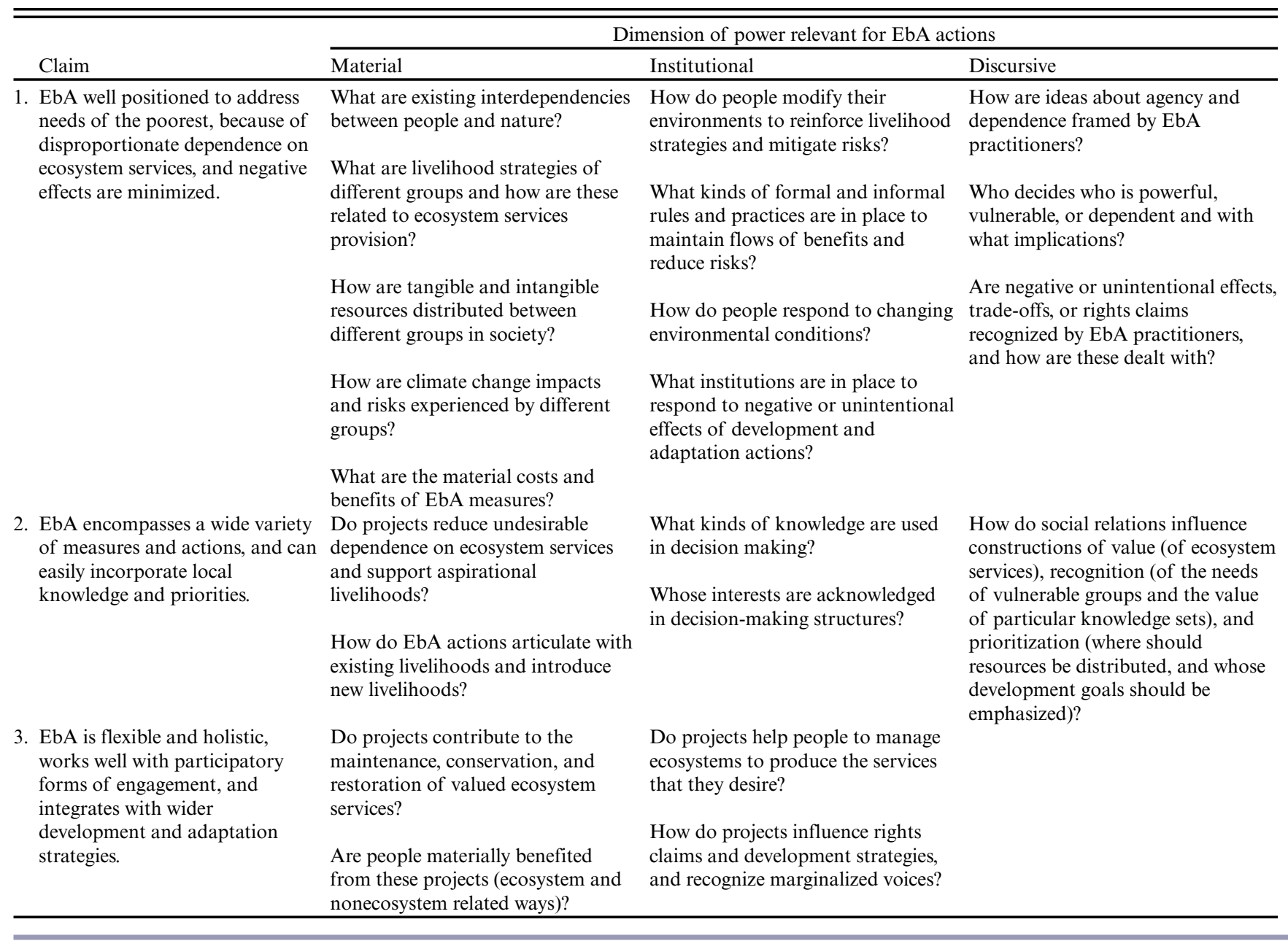

forms of agency, knowledge, and adaptive strategies. Such issues link to emerging scholarship on civic ecologies, practices of commoning, and ongoing colonization (Todd 2016, Wamsler and Raggers 2018).

There appears to be a mismatch between EbA framed and justified as people's static dependency on ecological resources, which are increasingly destabilized by climate change, and claims that it enables social benefits. This situation risks overlooking the dynamics of power that condition dependency, including the unintentional exacerbation of vulnerability and the marginalization of poor people's aspirations and priorities (Yang et al. 2013). Importantly, expressions of agency in relation to climate change, as stipulated by empowerment theory, run counter to narratives of dependency observed in EbA scholarship. EbA appears to position marginalized people as inevitably dependent on ecological resources. Without denying the material realities of ecosystem-service dependency (when carefully differentiated according to different groups of people and the specific access entitlements they enjoy), empowerment scholarship nuances such narratives. By not framing vulnerability as static and shaped by external forces, EbA can support people's own, subjective aspirations and strategies (de Hann and Zoomers 2005).
Because EbA only recognizes, and acts upon, the ecological basis of vulnerability, how ecology, and moreover people's relationships with ecologies, including ecosystem services, is framed has consequences. Converting such ecological knowledge into social benefits is not straightforward. The literature highlights how framing ecology as something separate, ideally untouched by humans, may be disempowering because it may conceal historical, cultural, and political ways marginalized people relate to ecologies (Ernstson 2013). A key step for EbA research and practice is recognizing people's diverse relationships with ecologies, and how these relate to their marginalization and vulnerability (Díaz et al. 2018).

\section{Institutions}

In terms of institutional advantages, EbA may help to lay the groundwork for progressive social change by contributing to just decision making, ensuring representation of marginal voices, renegotiating access to desired resources, and enabling people to make choices according to their own aspirations and priorities. Such negotiation, contestation, and claim making can be related to relevant dimensions of natural resource governance, livelihood security, and broader social-ecological relations that overlap with 
EbA action. Such progress is unlikely to be the automatic benefit of a green approach. Instead it must be carefully cultivated, recognized, and negotiated.

We would like to reaffirm that inclusive, formal EbA engagements are important. However, without recognition of the dynamics of social change, and how these are embedded into adaptation processes, our findings suggest that adaptation projects are likely to be marginal to empowerment. Projects are especially unlikely to contribute to empowering processes if they do not recognize people's own claims and projects, or that special provisions may be necessary to address the needs of the most vulnerable, for example, through targeted social protection (Davies et al. 2009). Our study documented few instances of an EbA action that acknowledged or explicitly contributed to people's ongoing political struggles aimed at disrupting the social structures critical for adaptation-relevant rights and recognition. The potential of EbA to facilitate empowerment, especially recognition of diverse priorities and knowledge, may be limited by scale mismatches, both spatial (a mismatch between the scale of the social structure that maintains unequal access, representation and recognition, and EbA engagements) and temporal (legacy effects of historical power relations and the time horizons of EbA interventions).

\section{Challenges}

We recognize that such findings are challenging. One challenge identified in this paper lies in recognizing the differential nature of vulnerability, and its basis within power relations. The latter operate, in part, within social-ecological relations, and our study highlights how different groups may subjectively view these relations, and attempt to alter landscapes accordingly. This, in turn, may consciously or unwittingly constrain the agency of other groups (Leach et al. 1999). Empowerment of particular, perhaps disproportionately, marginalized or dependent groups may lead to new or renewed tensions, arguments, and conflicts over ecosystem services. Furthermore, not all empowerment processes overlap with the interests of EbA advocates. Paying attention to bottom-up processes by facilitating processes of selfdetermination or process ownership is likely to have most potential to contribute to empowerment, but may conflict with the interests of EbA practitioners, potentially introducing dilemmas.

Another challenge relates to potential subjective, unwanted forms of empowerment, such as resistance to external interventions. This raises questions about trade-offs and how conflicting priorities are negotiated between EbA practitioners and their nominal beneficiaries, particularly when power relations are asymmetrical (Dawson et al. 2017). Preoccupation with social benefits and their achievement in the context of EbA could lead to a back loop in which the empowerment of vulnerable people increases the recognition and management of ecosystems services (Whatmore and Landström 2011). However, given people's diverse strategies with respect to social-ecological relations, this may not be guaranteed. As green may not necessarily be fair, fair, in turn, may not necessarily be green.

\section{Next steps}

Further research could focus on how tensions and trade-offs between ecological and social conditions will be addressed if EbA is reframed to more explicitly acknowledge social processes and strategies. The objective of our work is to enhance EbA by taking more account of social dynamics and power. Future studies could seek to introduce a clearer focus on understanding ecosystems and their interactions with climate change, perhaps by incorporating marginalized people into participatory knowledge production processes (Brisbois and de Loë 2016).

The present study relates to a broader discussion on the interplay between scholarship that recognizes the biophysical basis of people's well-being, namely social-ecological systems research, and scholarship that focusses on the social construction of vulnerability and transformative adaptation (O'Brien 2012). Indeed, framing empowerment as the process through which previously denied rights such as access to household food and water security are won, achieved through collective organization, is related to Pelling's focus on transformative adaptation as a wider struggle for rights and recognition (Pelling 2011).

Two points of interest stand out in positioning EbA in relation to such efforts. First, transformative approaches to adaptation may be more relevant to the most vulnerable people, by focusing on discursive and institutional relations that may be impeding more urgent and socially just adaptation trajectories (Pelling 2011). Second, transformative adaptation, a form of more radical social change, may entail recognizing the relative, complementary, and bounded contributions of ecology to mediating exposure and capability, i.e., vulnerability, in a changing climate (Pelling et al. 2015). An approach that tries to bring about social change exclusively through attention to managing social-ecological relations may not always be an appropriate vehicle for such endeavors (Berbés-Blásquez et al. 2016, Wieland et al. 2016). Some definitions of EbA already recognize the need to embed a focus on ecology within wider efforts. Such an awareness of complementarity can assist empowerment efforts.

\section{CONCLUSIONS}

In this paper, we presented a review of the predominant meanings and interlinkages between the concepts of EbA and empowerment. With this foundation, we discussed how the lens of empowerment could be (better) integrated into the conceptualization of EbA, and suggested some key dimensions through which this could be supported.

We find that the biophysical dimension of EbA, i.e., ecosystem services provision, is unlikely to contribute to empowerment unless there is a conscious decision to address its institutional and discursive elements. In addition, our results show that this empowerment lens offers a nuanced way to unpack the EbA construct, by addressing the social processes and strategies that are fundamental to the conceptualization of both $\mathrm{EbA}$ and empowerment. In this context, empowerment theory can help us to think more carefully about social relations. In doing so, we can explore how a marginalized individual or social group bears the brunt of disadvantageous social relations that have concrete implications for climate change impacts and potential responses, including those that occur through social-ecological relations.

We also find that considering EbA as embedded within broader, contextual power dynamics that evolve across the socialecological relations of a given place increases our understanding of how an EbA action can influence marginalized people's agency in addressing climate change, and challenge inequalities. In particular, we show how EbA actions may contribute to broader processes of empowerment. 
If it is to fully acknowledge the implications of empowerment theory, EbA should give pride of place to people's subjective aspirations and their diverse strategies, in the context of power structures that condition access to resources and shape the broader norms and entitlement of different groups in society. Although probably marginal to such endeavors, EbA represents an opportunity to support people's livelihood strategies and claims to rights in a dynamic and uncertain biophysical security and justice context.

Our proposed conceptualization is relevant for ecosystem services practitioners and scholars who are looking to unpack the key facets of social change, and how they may be achieved through EbA. It also makes the case for increased consideration of the strategies of marginalized groups, and the social processes that condition their achievement. Incorporating an empowerment lens leads to a broader consideration of issues of power, especially the way that marginalized groups' agency, access, and aspirations are conditioned by social structures that may prevent strategic adaptation choices.

Responses to this article can be read online at: http://www.ecologyandsociety.org/issues/responses. php/10854

\section{Acknowledgments:}

The work was financially supported by the Linnaeus Centre LUCID, funded by the Swedish Research Council Formas.

\section{LITERATURE CITED}

Adger, W. N., N. W. Arnell, and E. L. Tompkins. 2005. Successful adaptation to climate change across scales. Global Environmental Change 15(2):77-86. https://doi.org/10.1016/j.gloenvcha.2004.12.005

Agarwal, B. 2010. Gender and green governance: the political economy of women's presence within and beyond community forestry. Oxford University Press, Oxford, UK. https://doi. org/10.1093/acprof:oso/9780199569687.001.0001

Ahammad, R. 2011. Constraints of pro-poor climate change adaptation in Chittagong City. Environment and Urbanization 23 (2):503-515. https://doi.org/10.1177/0956247811414633

Ahmed, S. 2001. Empowering rural women? Policies, institutions, and gendered outcomes in natural resources management. Development in Practice 11(4):535-537. https://doi. org/10.1080/09614520120066800

Amundsen, H., F. Berglund, and H. Westskogh. 2010. Overcoming barriers to climate change adaptation-a question of multilevel governance? Environment and Planning C: Politics and Space 28(2):276-289. https://doi.org/10.1068/c0941

Andrade, A., R. Córdoba, R. Dave, P. Girot, B. HerreraFernandez, R. Munroe, J. Oglethorpe, P. Paaby, E. Pramova, J. Watson, W. Vergar. 2011. Draft principles and guidelines for integrating ecosystem-based approaches to adaptation in project and policy design. Centro Agronómico Tropical de Investigación y Enseñanza, Turrialba, Costa Rica.
Arnstein, S. R. 1969. A ladder of citizen participation. Journal of the American Planning Association 35(4):216-224. https://doi. org/10.1080/01944366908977225

Atteridge, A., and E. Remling. 2018. Is adaptation reducing vulnerability or redistributing it? Climate Change 9(1).

Béné, C., R. M. Al-Hassan, O. Amarasinghe, P. Fong, J. Ocran, E. Onumah, R. Ratuniata, T. Van Tuyen, J. A. McGregor, and D. J. Mills. 2016. Is resilience socially constructed? Empirical evidence from Fiji, Ghana, Sri Lanka, and Vietnam. Global Environmental Change 38:153-170. https://doi.org/10.1016/j. gloenvcha.2016.03.005

Berbés-Blásquez, M., J. A. González, and U. Pascual. 2016. Towards an ecosystem services approach that addresses social power relations. Current Opinion in Environmental Sustainability 19:134-143. https://doi.org/10.1016/j.cosust.2016.02.003

Bhave, A. G., A. Mishra, and A. Groot. 2013. Sub-basin scale characterization of climate change vulnerability, impacts and adaptation in an Indian River basin. Regional Environmental Change 13(5):1087-1098. https://doi.org/10.1007/s10113-013-0416-8

Bourdieu, P. 2014. On the state: lectures at the College de France, 1989-1992. Polity, Cambridge, UK.

Boyd, E. 2017. Climate adaptation: holistic thinking beyond technology. NatureClimate Change 7(2):97-98. https://doi. org/10.1038/nclimate3211

Brink, E., T. Aalders, D. Ádám, R. Feller, Y. Henselek, A. Hoffmann, K. Ibe, A. Matthey-Doret, M. Meyer, N. L. Negrut, A. L. Rau, B. Riewerts, L. von Schuckmann, S. Törnros, H. von Wehrden, D. J. Abson, and C. Wamsler. 2016. Cascades of green: a review of ecosystem-based adaptation in urban areas. Global Environmental Change 36:111-123. https://doi.org/10.1016/j. gloenvcha.2015.11.003

Brisbois, M. C., and R. C. de Loë. 2016. Power in collaborative approaches to governance for water: a systematic review. Society and Natural Resources 29(7):775-790. https://doi. org/10.1080/08941920.2015.1080339

Broto, V. C., E. Boyd, and J. Ensor. 2015. Participatory urban planning for climate change adaptation in coastal cities: lessons from a pilot experience in Maputo, Mozambique. Current Opinion in Environmental Sustainability 13:11-18. https://doi.org/10.1016/ j.cosust.2014.12.005

Brugger, J., and M. Crimmins. 2013. The art of adaptation: living with climate change in the rural American Southwest. Global Environmental Change 23(6):1830-1840. https://doi.org/10.1016/ j.gloenvcha.2013.07.012

Cannon, T. 1994. Vulnerability analysis and the explanation of "natural" disasters. Pages 13-30 in A. Varley, editor. Disasters, development and environment Wiley, Hoboken, New Jersey, USA.

Carpenter, S. R., C. Folke, A. Norström, O. Olsson, L. Schultz, B. Agarwal, P. Balvanera, B. Campbell, J. C. Castilla, W. Cramer, R. DeFries, P. Eyzaguirre, T. P. Hughes, S. Polasky, Z. Sanusi, R. Scholes, and M. Spierenburg. 2012. Program on ecosystem change and society: an international research strategy for integrated social-ecological systems. Current Opinion in Environmental Sustainability 4(1):134-138. https://doi.org/10.1016/j.cosust.2012.01.001 
Chambers, R., and G. Conway. 1991. Sustainable rural livelihoods: practical concepts for the 21 st century. IDS Discussion Paper 296:1-29.

Chong, J. 2014. Ecosystem-based approaches to climate change adaptation: progress and challenges. International Environmental Agreements: Politics, Law and Economics 14(4):391-405. https:// doi.org/10.1007/s10784-014-9242-9

Chu, E., I. Anguelovski, and J. Carmin. 2016. Inclusive approaches to urban climate adaptation planning and implementation in the Global South. Climate Policy 16 (3):372-392. https://doi.org/10.1080/14693062.2015.1019822

Codjoe, S. N. A., L. K. Atidoh, and V. Burkett. 2012. Gender and occupational perspectives on adaptation to climate extremes in the Afram Plains of Ghana. Climatic Change 110(1-2):431-454. https://doi.org/10.1007/s10584-011-0237-z

Coirolo, C., and A. Rahman. 2014. Power and differential climate change vulnerability among extremely poor people in northwest Bangladesh: lessons for mainstreaming. Climate and Development 6(4):336-344. https://doi.org/10.1080/17565529.2014.934774

Convention on Biological Diversity (CBD). 2009. Connecting biodiversity and climate change mitigation and adaptation: report of the second ad hoc technical expert group on biodiversity and climate change. Secretariat of the Convention on Biological Diversity, Montréal, Québec, Canada.

Convention on Biological Diversity (CBD). 2010. Decision adopted by the conference of the parties to the convention on biological diversity at its 10th meeting; X/33. Biodiversity and climate change. Conference of the Parties to the Convention on Biological Diversity, United Nations Environment Programme, Nagoya, Japan. http://www.cbd.int/doc/decisions/cop-10/cop-10dec-33-en.pdf

Conway, D., and J. Mustelin. 2014. Strategies for improving adaptation practice in developing countries. Nature Climate Change 4(5):339-342. https://doi.org/10.1038/nclimate2199

Davies, M., K. Oswald, and T. M. Ids. 2009. Climate change adaptation, disaster risk reduction and social protection. Change 2:201-217.

Dawson, N. M., K. Grogan, A. Martin, O. Mertz, M. Pasgaard, and L. V. Rasmussen. 2017. Environmental justice research shows the importance of social feedbacks in ecosystem service tradeoffs. Ecology and Society 22(3):12. https://doi.org/10.5751/ ES-09481-220312

de Hann, L., and A. Zoomers. 2005. Exploring the frontier of livelihoods research. Development and Change 36(1):27-47. https://doi.org/10.1111/j.0012-155X.2005.00401.X

Díaz, S., U. Pascual, M. Stenseke, B. Martín-López, R. T. Watson, Z. Molnár, R. Hill, K. M. A. Chan, I. A. Baste, K. A. Brauman, S. Polasky, A. Church, M. Lonsdale, A. Larigauderie, P. W. Leadley, A. P. E. Van Oudenhoven, F. Van Der Plaat, M. Schröter, S. Lavorel, Y. Aumeeruddy-Thomas, E. Bukvareva, K. Davies, S. Demissew, G. Erpul, P. Failler, C. A. Guerra, C. L. Hewitt, H. Keune, S. Lindley, and Y. Shirayama. 2018. Assessing nature's contributions to people: recognizing culture, and diverse sources of knowledge, can improve assessments. Science 359 (6373):270-272. https://doi.org/10.1126/science.aap8826
Doswald, N., R. Munroe, D. Roe, A. Giuliani, I. Castelli, J. Stephens, I. Möller, T. Spencer, B. Vira, and H. Reid. 2014. Effectiveness of ecosystem-based approaches for adaptation: review of the evidence-base. Climate and Development 6 (2):185-201. https://doi.org/10.1080/17565529.2013.867247

Drydyk, J. 2008. Durable empowerment. Journal of Global Ethics 4(3):231-245. https://doi.org/10.1080/174496620802496354

Eakin, H., S. Eriksen, P. O. Eikeland, and C. Øyen. 2011. Public sector reform and governance for adaptation: implications of new public management for adaptive capacity in Mexico and Norway. Environmental Management 47(3):338-351. https://doi.org/10.1007/ $\underline{\mathrm{s} 00267-010-9605-0}$

Eakin, H. C., M. C. Lemos, and D. R. Nelson. 2014. Differentiating capacities as a means to sustainable climate change adaptation. Global Environmental Change 27(1):1-8. https://doi.org/10.1016/j.gloenvcha.2014.04.013

Ensor, J., and R. Berger. 2009. Understanding climate change adaptation: lessons from community-based approaches. Practical Action, Rugby, UK. https://doi.org/10.3362/9781780440415

Ensor, J. E., S. E. Park, E. T. Hoddy, and B. D. Ratner. 2015. A rights-based perspective on adaptive capacity. Global Environmental Change 31:38-49. https://doi.org/10.1016/j. gloenvcha.2014.12.005

Eriksen, S., and J. Lind. 2009. Adaptation as a political process: adjusting to drought and conflict in Kenya's drylands. Environmental Management 43(5):817-835. https://doi.org/10.1007/ s00267-008-9189-0

Eriksen, S. H., A. J. Nightingale, and H. Eakin. 2015. Reframing adaptation: the political nature of climate change adaptation. Global Environmental Change 35:523-533. https://doi.org/10.1016/ j.gloenvcha.2015.09.014

Eriksen, S. H., and K. O'Brien. 2007. Vulnerability, poverty and the need for sustainable adaptation measures. Climate Policy 7 (4):337-352. https://doi.org/10.3763/cpol.2007.0717

Ernstson, H. 2013. The social production of ecosystem services: a framework for studying environmental justice and ecological complexity in urbanized landscapes. Landscape and Urban Planning 109(1):7-17. https://doi.org/10.1016/j.landurbplan.2012.10.005

Eyben, R., C. Harris, and J. Pettit. 2006. Introduction: exploring power for change. IDS Bulletin 37(6):1-10. https://doi. org/10.1111/j.1759-5436.2006.tb00318.x

Forsyth, T. 2014. How is community-based adaptation 'scaled up' in environmental risk assessment? Lessons from ecosystem-based adaptation. Pages 88-102 in E. L. F. Schipper, J. Ayers, H. Reid, S. Huq, and A. Rahman, editors. Community-based adaptation to climate change: scaling it up. Routledge, London, UK.

Fraser, N. 1997. Justice interruptus: rethinking key concepts of a "postsocialist" age. Routledge, London, UK.

Gabrielsson, S., and V. Ramasar. 2013. Widows: agents of change in a climate of water uncertainty. Journal of Cleaner Production 60:34-42. https://doi.org/10.1016/j.jclepro.2012.01.034

Gaillard, J. C., C. Monteil, A. Perrillat-Collomb, S. Chaudhary, M. Chaudhary, O. Chaudhary, F. Giazzi, and J. R. D. Cadag. 2013. Participatory 3-dimension mapping: a tool for encouraging 
multi-caste collaboration to climate change adaptation and disaster risk reduction. Applied Geography 45:158-166. https:// doi.org/10.1016/j.apgeog.2013.09.009

Gaventa, J. 2006. Finding the spaces for change: a power analysis. IDS Bulletin 37(6):23-33. https://doi.org/10.1111/j.1759-5436.2006. $\underline{\mathrm{tb} 00320 . \mathrm{x}}$

Giddens, A. 1984. The constitution of society: outline of the theory of structuration. University of California Press, Berkeley, California, USA.

Girot, P. 2013. Integrating community-based adaptation and DRR approaches into ecosystem-based approaches To adaptation. Experiences From the field. Input Paper prepared for The Global Assessment Report On Disaster Risk Reduction 2015. United Nations Office for Disaster Risk Reduction, Geneva, Switzerland. [online] URL: https://www.unisdr.org/we/inform/publications/50016

Harries, T., and E. Penning-Rowsell. 2011. Victim pressure, institutional inertia and climate change adaptation: the case of flood risk. Global Environmental Change 21(1):188-197. https:// doi.org/10.1016/j.gloenvcha.2010.09.002

Haugaard, M. 2010. Power: a 'family resemblance' concept. European Journal of Cultural Studies 13(4):419-438. https://doi. org/10.1177/1367549410377152

Hayward, C., and S. Lukes. 2008. Nobody to shoot? Power, structure, and agency: a dialogue. Journal of Power 1(1):5-20. https://doi.org/10.1080/17540290801943364

Jones, H. P., D. G. Hole, and E. S. Zavaleta. 2012. Harnessing nature to help people adapt to climate change. Nature Climate Change 2(7):504-509. https://doi.org/10.1038/nclimate1463

Kabeer, N. 1999. Resources, agency, achievements: reflections on the measurement of women's empowerment. Development and Change 30(3):435-464. https://doi.org/10.1111/1467-7660.00125

Leach, M., R. Mearns, and I. Scoones. 1999. Environmental entitlements: dynamics and institutions in community-based natural resource management. World Development 27(2):225247. https://doi.org/10.1016/S0305-750X(98)00141-7

López-Marrero, T., and B. Wisner. 2012. Not in the same boat: disasters and differential vulnerability in the insular Caribbean. Caribbean Studies 40(2):129-168. https://doi.org/10.1353/ crb.2012.0034

Lovell, E. and V. Le Masson. 2014. Equity and inclusion in disaster risk reduction: building resilience for all. Climate Development Knowledge Network and Overseas Development Institute, London, UK.

Maes, J., and S. Jacobs. 2017. Nature-based solutions for Europe's sustainable development. Conservation Letters 10(1):121-124. https://doi.org/10.1111/conl.12216

Manuel-Navarrete, D. 2010. Power, realism, and the ideal of human emancipation in a climate of change. Climate Change 1 (6):781-785. https://doi.org/10.1002/wcc.87

Mercer, J., I. Kelman, B. Alfthan, and T. Kurvits. 2012. Ecosystem-based adaptation to climate change in Caribbean small island developing states: integrating local and external knowledge. Sustainability 4(8):1908-1932. https://doi.org/10.3390/ su4081908
Moser, C. O. N. 1998. The asset vulnerability framework: reassessing urban poverty reduction strategies. World Development 26(1):1-19. https://doi.org/10.1016/S0305-750X(97) 10015-8

Mukheibir, P., N. Kuruppu, A. Gero, and J. Herriman. 2013. Overcoming cross-scale challenges to climate change adaptation for local government: a focus on Australia. Climatic Change 121 (2):271-283. https://doi.org/10.1007/s10584-013-0880-7

Munang, R., J. Andrews, K. Alverson, and D. Mebratu. 2014. Harnessing ecosystem-based adaptation to address the social dimensions of climate change. Environment: Science and Policy for Sustainable Development 56(1):18-24. https://doi. org/10.1080/00139157.2014.861676

Nagoda, S. 2015. New discourses but same old development approaches? Climate change adaptation policies, chronic food insecurity and development interventions in northwestern Nepal. Global Environmental Change 35:570-579. https://doi.org/10.1016/ j.gloenvcha.2015.08.014

Newsham, A. J., and D. S. G. Thomas. 2011. Knowing, farming and climate change adaptation in north-central Namibia. Global Environmental Change 21(2):761-770. https://doi.org/10.1016/j. gloenvcha.2010.12.003

Nightingale, A. J. 2017. Power and politics in climate change adaptation efforts: struggles over authority and recognition in the context of political instability. Geoforum 84:11-20. https://doi. org/10.1016/j.geoforum.2017.05.011

O'Brien, K. 2012. Global environmental change II: from adaptation to deliberate transformation. Progress in Human Geography 36(5):667-676. https://doi.org/10.1177/0309132511425767

Olsson, L., M. Opondo, P. Tschakert, A. Agrawal, S. H. Eriksen, S. Ma, L. N. Perch, and S. A. Zakieldeen. 2014. Livelihoods and poverty. Pages 793-832 in C. B. Field, V. R. Barros, D. J. Dokken, K. J. Mach, M. D. Mastrandrea, T. E. Bilir, M. Chatterjee, K. L. Ebi, Y. O. Estrada, R. C. Genova, B. Girma, E. S. Kissel, A. N. Levy, S. MacCracken, P. R. Mastrandrea, and L. L. White, editors. Climate change 2014: impacts, adaptation and vulnerability. Part A: global and sectoral aspects. Contribution of working Group II to the Fifth Assessment Report of the Intergovernmental Panel on Climate Change. Cambridge University Press, Cambridge, UK.

Onta, N., and B. P. Resurreccion. 2011. The role of gender and caste in climate adaptation strategies in Nepal: emerging change and persistent inequalities in the far-western region. Mountain Research and Development 31(4):351-356. https://doi.org/10.1659/ MRD-JOURNAL-D-10-00085.1

Paavola, J., and W. N. Adger. 2006. Fair adaptation to climate change. Ecological Economics 56(4):594-609. https://doi. org/10.1016/j.ecolecon.2005.03.015

Pansardi, P. 2012. Power to and power over: two distinct concepts of power? Journal of Political Power 5(1):73-89. https://doi. org/10.1080/2158379X.2012.658278

Patenaude, G., and K. Lewis. 2014. The impacts of Tanzania's natural resource management programmes for ecosystem services and poverty alleviation. International Forestry Review 16 (4):459-473. https://doi.org/10.1505/146554814813484077 
Pelling, M. 2011. Adaptation to climate change: from resilience to transformation. Routledge, London, UK.

Pelling, M., K. O'Brien, and D. Matyas. 2015. Adaptation and transformation. Climatic Change 133(1):113-127. https://doi. org/10.1007/s10584-014-1303-0

Petheram, L., K. K. Zander, B. M. Campbell, C. High, and N. Stacey. 2010. 'Strange changes': indigenous perspectives of climate change and adaptation in NE Arnhem Land (Australia). Global Environmental Change 20(4):681-692. https://doi. org/10.1016/j.gloenvcha.2010.05.002

Polishchuk, Y., and F. Rauschmayer. 2012. Beyond "benefits"? Looking at ecosystem services through the capability approach. Ecological Economics 81:103-111. https://doi.org/10.1016/j. ecolecon.2012.06.010

Preiser, R., L. M. Pereira, and R. (O.) Biggs. 2017. Navigating alternative framings of human-environment interactions: variations on the theme of 'Finding Nemo.' Anthropocene 20:83-87. https://doi.org/10.1016/j.ancene.2017.10.003

Pretty, J., and H. Ward. 2001. Social capital and the environment. World Development 29(2):209-227. https://doi.org/10.1016/ $\underline{\mathrm{S} 0305-750 \mathrm{X}(00) 00098-\mathrm{X}}$

Reid, H. 2016. Ecosystem- and community-based adaptation: learning from community-based natural resource management. Climate and Development 8:4-9. https://doi.org/10.1080/1756552$\underline{9.2015 .1034233}$

Renaud, F. G., K. Sudmeier-Rieux, and M. Estrella, editors. 2013. The role of ecosystems in disaster risk reduction. United Nations University Press, Tokyo, Japan.

Ribot, J. 2010. Vulnerability does not just fall from the sky: toward multi-scale, pro-poor climate policy. Pages 47-74 in R. Mearns and A. Norton, editors. Social dimensions of climate change: equity and vulnerability in a warming world. The World Bank, Washington, D.C., USA.

Ribot, J. 2014. Cause and response: vulnerability and climate in the Anthropocene. Journal of Peasant Studies 41(5):667-705. https://doi.org/10.1080/03066150.2014.894911

Roberts, D., R. Boon, N. Diederichs, E. Douwes, N. Govender, A. Mcinnes, C. Mclean, S. O'Donoghue, and M. Spires. 2012. Exploring ecosystem-based adaptation in Durban, South Africa: "learning-by-doing" at the local government coal face. Environment and Urbanization 24(1):167-195. https://doi. org/10.1177/0956247811431412

Roy, M., and H. D. Venema. 2002. Reducing risk and vulnerability to climate change in India: the capabilities approach. Working in Gender \& Development 10(2):78-83. https://doi.org/10.3362/978$\underline{1780440088.003}$

Schleicher, J., M. Schaafsma, N. D. Burgess, C. Sandbrook, F. Danks, C. Cowie, and B. Vira. 2018. Poorer without It? The neglected role of the natural environment in poverty and wellbeing. Sustainable Development 26(1):83-98. https://doi. org/10.1002/sd.1692

Schlosberg, D. 2004. Reconceiving environmental justice: global movements and political theories. Environmental Politics 13 (3):517-540. https://doi.org/10.1080/0964401042000229025
Schwarz, A.-M., C. Béné, G. Bennett, D. Boso, Z. Hilly, C. Paul, R. Posala, S. Sibiti, and N. Andrew. 2011. Vulnerability and resilience of remote rural communities to shocks and global changes: empirical analysis from Solomon Islands. Global Environmental Change 21(3):1128-1140. https://doi.org/10.1016/ j.gloenvcha.2011.04.011

Seddon, N., X. Hou-Jones, T. Pye, H. Reid, D. Roe, D. Mountain, and A. R. Rizvi. 2016. Ecosystem-based adaptation: a win-win formula for sustainability in a warming world? IIED Briefing. International Institute for Environment and Development, London, UK.

Sen, A. 2001. Development as freedom. Second edition. Oxford University Press, Oxford, UK.

Snorek, J., F. G. Renaud, and J. Kloos. 2014. Divergent adaptation to climate variability: a case study of pastoral and agricultural societies in Niger. Global Environmental Change 29:371-386. https://doi.org/10.1016/j.gloenvcha.2014.06.014

Sova, C. A., A. Helfgott, A. S. Chaudhury, D. Matthews, T. F. Thornton, and S. J. Vermeulen. 2015. Multi-level stakeholder influence mapping: visualizing power relations across actor levels in Nepal's agricultural climate change adaptation regime. Systemic Practice and Action Research 28(4):383-409. https://doi. org/10.1007/s11213-014-9335-y

Sovacool, B. K., and B.-O. Linnér. 2016. The political economy of climate change adaptation. Palgrave Macmillan, Basingstoke, UK. https://doi.org/10.1057/9781137496737

Stirling, A. 2014. Transforming power: social science and the politics of energy choices. Energy Research \& Social Science 1:83-95. https://doi.org/10.1016/j.erss.2014.02.001

Stirling, A. 2015. Emancipating transformation: from controlling 'the transition' to culturing plural radical progress. Pages 54-67 in I. Scoones, M. Leach, and P. Newell, editors. The politics of green transformations. Pathways to sustainability. Routledge, London, UK.

Tanner, T., D. Lewis, D. Wrathall, R. Bronen, N. Cradock-Henry, S. Huq, C. Lawless, R. Nawrotzki, V. Prasad, M. A. Rahman, R. Alaniz, K. King, K. McNamara, M. Nadiruzzaman, S. HenlyShepard, and F. Thomalla. 2015. Livelihood resilience in the face of climate change. Nature Climate Change 5:23-26. https://doi. org/10.1038/nclimate2431

Tidball, K. G., and M. E. Krasny. 2014. Greening in the Red Zone: disaster, resilience and community greening. Springer, Dordrecht, The Netherlands. https://doi.org/10.1007/978-90-481-9947-1

Tilly, C. 2005. Identities, boundaries, and social ties. Paradigm, Boulder, Colorado, USA.

Todd, Z. 2016. An indigenous feminist's take on the ontological turn: ontology is just another word for colonialism. Journal of Historical Sociology 29(1):4-22. https://doi.org/10.1111/johs.12124

Tompkins, E. L., and W. N. Adger. 2004. Does adaptive management of natural resources enhance resilience to climate change? Ecology and Society 9(2):10. https://doi.org/10.5751/ ES-00667-090210

Uy, N., R. Shaw, and Y. Takeuchi. 2012. Livelihoods: linking livelihoods and ecosystems for enhanced disaster management. 
Pages 131-143 in R. Shaw and P. Tran, editors. Environment Disaster Linkages (Community, Environment and Disaster Risk Management, Volume 9). Emerald Group, Bingley, UK. https:// doi.org/10.1108/S2040-7262(2012)0000009014

Veneklasen, L. 2006. Last word - How does change happen. Development 49(1):155-161. https://doi.org/10.1057/palgrave. development.1100231

Vignola, R., B. Locatelli, C. Martinez, and P. Imbach. 2009. Ecosystem-based adaptation to climate change: what role for policy-makers, society and scientists? Mitigation and Adaptation Strategies for Global Change 14(8):691-696. https://doi. org/10.1007/s11027-009-9193-6

Vogel, C., S. C. Moser, R. E. Kasperson, and G. D. Dabelko. 2007. Linking vulnerability, adaptation, and resilience science to practice: pathways, players, and partnerships. Global Environmental Change 17(3-4):349-364. https://doi.org/10.1016/j. gloenvcha.2007.05.002

Wamsler, C., and E. Brink. 2014. Interfacing citizens' and institutions' practice and responsibilities for climate change adaptation. Urban Climate 7:64-91. https://doi.org/10.1016/j. $\underline{\text { uclim.2013.10.009 }}$

Wamsler, C., and S. Raggers. 2018. Principles for supporting citycitizen commoning for climate adaptation: from adaptation governance to sustainable transformation. Environmental Science and Policy 85:81-89. https://doi.org/10.1016/j.envsci.2018.03.021

Watts, M. J., and H. J. Bohle. 1993. The space of vulnerability: the causal structure of hunger and famine. Progress in Human Geography 17(1):43-67. https://doi.org/10.1177/030913259301700103

Whatmore, S. J., and C. Landström. 2011. Flood apprentices: an exercise in making things public. Economy and Society 40 (4):582-610. https://doi.org/10.1080/03085147.2011.602540

White, S. C. 2010. Analysing wellbeing: a framework for development practice. Development in Practice 20(2):158-172. https://doi.org/10.1080/09614520903564199

Wieland, R., S. Ravensbergen, E. J. Gregr, T. Satterfield, and K. M. A. Chan. 2016. Debunking trickle-down ecosystem services: the fallacy of omnipotent, homogeneous beneficiaries. Ecological Economics 121:175-180. https://doi.org/10.1016/j.ecolecon.2015.11.007

Wood, S. L. R., S. K. Jones, J. A. Johnson, K. A. Brauman, R. Chaplin-Kramer, A. Fremier, E. Girvetz, L. J. Gordon, C. V. Kappel, L. Mandle, M. Mulligan, P. O'Farrell, W. K. Smith, L. Willemen, W. Zhang, and F. A. DeClerck. 2018. Distilling the role of ecosystem services in the Sustainable Development Goals. Ecosystem Services 29:70-82. https://doi.org/10.1016/j.ecoser.2017.10.010

Yang, W., T. Dietz, D. B. Kramer, X. Chen, and J. Liu. 2013. Going beyond the Millennium Ecosystem Assessment: an index system of human well-being. PLoS ONE 8(5):e64582. https://doi. org/10.1371/journal.pone.0064582 